are sporadic, although autosomal dominant inheritance and germline mosaicisms have been described. The molecular basis of the disorder is a mutation of exon IIIa in the gene coding for fibroblast growth factor receptor-2 (FGFR-2), located on chromosome 10q26. Two FGFR2 gene missense mutations involving the substitution of one of two adjacent residues, Ser252Trp or Pro253Arg, result in increased affinity for the FGF ligand [3].

The clinical characteristics of Apert syndrome are severe craniosynostosis, midface hypoplasia with a flattened occiput, hypertelorism, mandibular prognathism, parrotbeak nose (figure $1 C$ ), cutaneous and osseous syndactyly of hands (figure ID) and feet, bilateral conductive deafness, scoliosis, lumbar spine lordosis, abnormalities of CNS, heart and genitourinary apparatus, turri-brachycephaly, proptosis, and down-slanting palpebral fissures [2]. Hydrocephalus and mental retardation may be present. Several skin manifestations have been reported, including hyperhidrosis, sebaceous gland changes, acute paronychia, plantar hyperkeratosis, hypopigmentation, dimples on knuckles, shoulders and elbows, interrupted eyebrows and excessive forehead wrinkling. Acne, one of the main skin symptoms, usually arises between 9 and 12 years of age; it is severe from onset and involves the chest and back as well as areas such as the forearms, buttocks and thighs.

It is closely related to the mutation of FGFR2, which is involved in cutaneous embryogenesis and is found in epidermis, hair follicles and sebaceous glands [3]. The increased affinity of FGF for the mutant receptor induces activation of different signal transduction pathways that lead to hyperexpression of melanocortin 5 receptor (which has a role in sebocyte differentiation and lipogenesis) and to increased production of interleukin 1-alpha (IL-1 $\alpha$ ), involved in keratinocyte proliferation and differentiation [3].

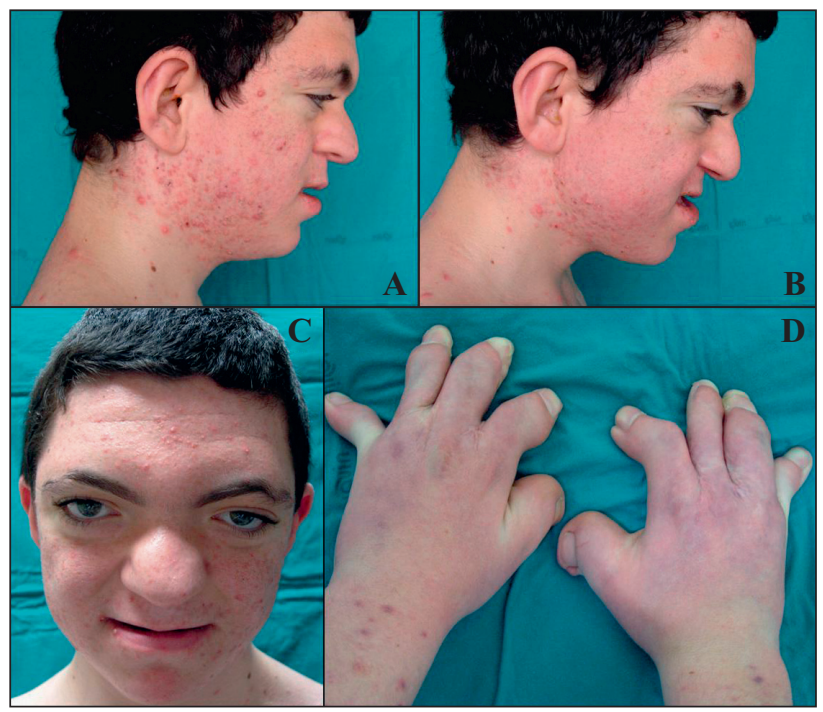

Figure 1. Papulo-pustular and nodular lesions on the face before treatment $(\mathbf{A})$ and 1 year from the end of isotretinoin therapy (B). Hypertelorism, mandibular prognathism, parrotbeak nose $(\mathbf{C})$ and cutaneous and osseous syndactyly of hands (D).
Acne in Apert syndrome is usually refractory to both topical and oral antibiotics. A single paper has described the effectiveness of three-phase contraceptives [4]. Several authors consider isotretinoin as the treatment of choice for acne in these patients $[2,5]$; the drug has also been reported to clear early acne in a 7-year-old child [5].

We report this case both because of the rare nature of the syndrome and to confirm that retinoids appear to be the most effective treatment in these patients, through attenuation of the FGFR2 pathway and regulation of the signal transduction involved in lipogenesis and in cell differentiation and proliferation [3].

Disclosure. Financial support: none. Conflict of interest: none.
Department of Dermatology,

Catholic University of the Sacred

Heart, Largo A. Gemelli 8, 00168 ,

Rome, Italy

<aparad@tin.it>
Andrea PARADISI

Francesca GHITTI

Rodolfo CAPIZZI

Barbara FOSSATI

Pier Luigi AMERIO

Cristina GUERRIERO
1. Herrmann J, Pallister PD, Opitz JM. Craniosynostosis and craniosynostosis syndromes. Rocky Mt Med J 1969; 66: 45-56.

2. Gilaberte $M$, Puig L, Alomar A. Isotretinoin Treatment of Acne in a Patient with Apert Syndrome. Pediatr Dermatol 2003;20: 443-6.

3. Melnik BC, Schmitz G, Zouboulis CC. Anti-acne agents attenuate FGFR2 signal transduction in acne. J Invest Dermatol 2009; 129: 186877

4. Hsieh $T, H o N$. Resolution of acne following therapy with an oral contraceptive in a patient with Apert syndrome. J Am Acad Dermatol 2005; 53: 173-4.

5. Campanati A, Marconi B, Penna L, Paolinelli M, Offidani A. Pronounced and early acne in Apert's syndrome: a case successfully treated with oral isotretinoin. Eur J Dermatol 2002; 12: 496-8.

doi: $10.1684 /$ ejd.2011.1365

\section{Modified shark island flap for combined nasal ala-perialar defects}

Although there is an increased public awareness and improved access to dermatologists, non-melanoma skin cancer continues to show increasing prevalence $[1,2]$. Head and neck are the preferential locations [3] and reconstruction of the nasal ala-perialar skin constitutes a challenge for dermatologic surgeons in order not to blunt the alar facial sulcus $[4,5]$. Trying to resolve this issue, Cvancara and Wentzell [6] recently described the shark island pedicle flap, a myocutaneous flap developed for specific combined nasal ala-perialar defects. The authors decided to use a variation of this flap, with exclusively subcutaneous random pattern vascularity, in the combined nasal ala-perialar defects of 2 patients.

Patient A, a 74 year-old female, presented with a basal cell carcinoma (BCC) of three years' evolution involving the concave intersection of the lateral nasal ala, nasal sidewall and cheek. After surgical removal, a $2.0 \times 1.0 \mathrm{~cm}$ 
defect was created. The width of the nasal ala portion of the defect was measured from the original location of the lateral alar sulcus to the medial edge of the wound. This area become the width of the "shark's snout". After careful undermining at the subcutaneous level, the back of the "shark" was pulled supero-medially into position and the $90^{\circ}$ rotation of the superior arm forced the alar portion of the flap to spontaneously tilt into a position perpendicular to the melolabial portion of the flap. The flap automatically creases, recreating the sulcus.

Patient B, a 75 year-old male, presented with a two year $\mathrm{BCC}$, also involving the concave intersection of the lateral nasal ala, nasal sidewall and cheek. After surgical removal a $1.0 \times 1.0 \mathrm{~cm}$ defect was created. Owing to the smaller size of the defect, the "shark's snout" and the "shark" island pedicle were developed from immediately surrounding skin. The back of the "shark" was pulled medially into position and the $45^{\circ}$ rotation of the superior arm was enough to recreate the sulcus. In both patients, after a 3 month follow-up period, no necrosis or other complications were noted and maintenance of the ala-perialar sulcus was observed (figure 1).

The Cvancara and Wentzell [5] myocutaneous shark island pedicle flap, depends on careful undermining beneath the muscle, preserving the deep myocutaneous vascular pedicle derived from the levator labii superioris. In the present study, the authors decided to use a modification of this flap, with the same anatomical and trigonometric principles but with exclusively subcutaneous random pattern vascularity. The execution of the flap is uniformly reproducible and allows variations, depending on the defect size. It is a reliable one stage repair of this cosmetically and functionally sensitive anatomic area, but is especially useful for more superficial defects. The exclusively random subcutaneous blood supply was enough to maintain the flap viability, with undermining being performed beneath the subcutaneous fat to achieve flap movement. The advancement and rotation is the basis of the flap movement, which

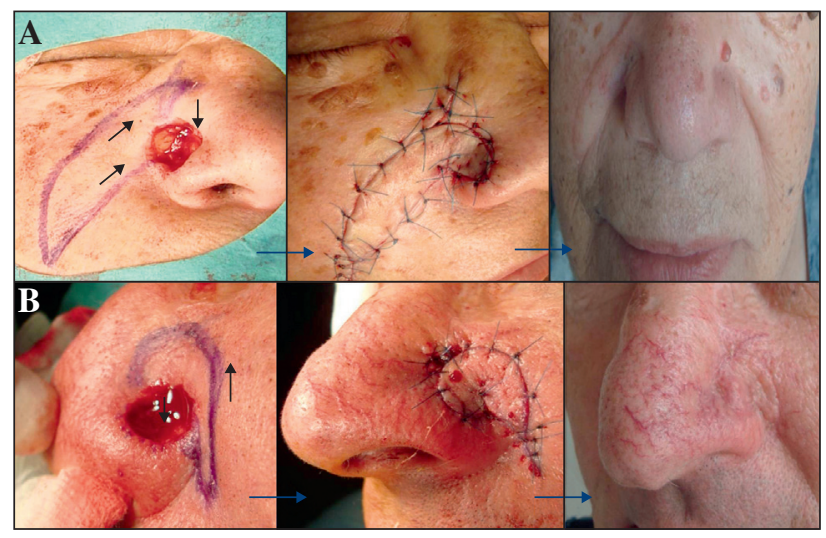

Figure 1. Patient A, after undermining at the subcutaneous level, the back of the "shark" was pulled supero-medially into position with a $90^{\circ}$ rotation, and the flap automatically creased, recreating the sulcus (A); Patient B, the island pedicle was developed from immediately surrounding skin, the back of the "shark" pulled medially into position and the $45^{\circ}$ rotation was enough to recreate the sulcus (B). In both, after a 3 month follow-up period, no complications were noted with maintenance of the ala-perialar sulcus.

spontaneously recreates and sharply defines the lateral ala and the alar facial sulcus. We consider it a value alternative, because of its simplicity and flexibility, constituting one more useful and reproducible option for single-stage closure of these defects.

Disclosure. Financial support: none. Conflict of interest: none.

Department of Dermatology and

Venereology,

Curry Cabral Hospital,

Rua da Beneficiência ${ }^{\circ} 8$,

1069-639 Lisboa, Portugal

<rodrigoaraujocarvalho@gmail.com>

1. Diepgen TL, Mahler V. The epidemiology of skin cancer. Br J Dermatol 2002; 146(Suppl. 61):1-6.

2. Lens MB, Dawes M. Global perspectives of contemporary epidemiological trends of cutaneous malignant melanoma. Br J Dermatol 2004; 150: 179-82.

3. Franceschi S, Levi F, Randimbison L, Lavecchia C. Site distribution of different types of skin cancer: new aetiological clues. Int Cancer $1996 ; 67: 24-8$.

4. Levasseur JG, Mellette JR Jr. Techniques for reconstruction of perialar and perialar-nasal ala combined defects. Dermatol Surg 2000; 26: 1019-23.

5. Haneke E. Dermatological surgery. Eur J Dermatol 2009; 19: $418-9$

6. Cvancara JL. and Wentzell JM. Shark Island Pedicle Flap for Repair of Combined Nasal Ala-Perialar Defects. Dermatol Surg 2006; 32: 726-9.

doi: $10.1684 /$ ejd.2011.1320

\section{Congenital erythropoietic porphyria and Parkinson's disease: clinical association in a patient with a long-term follow-up}

Congenital erythropoietic porphyria (CEP) is a rare autosomal recessive disorder due to a deficiency of uroporphyrinogen III synthase. Manifestations of CEP include severe photosensitivity, leading to blisters, scarring and mutilations, haemolytic anaemia, erythrodontia and ocular and skeletal involvement. In contrast to other porphyrias, neurological engagement has not been previously reported. The overall life expectancy is shortened in the most severe cases due to haematological complications and increased risks of infection [1].

We present a male patient with CEP, with a long followup, who developed Parkinson's disease (PD) decades later. He presented with photosensitivity and dark urine at the age of 5 months. His clinical, biochemical, enzymatic and genetic characteristics were consistent with CEP [2]. Clinical manifestations and porphyrin concentrations had been stable in the last years (mean total porphyrins in urine: 670 nmol/mmol creatinine). In May 2010, aged 49, he presented with tremor and slowness of movement. Neurological examination revealed intentional and postural tremor, rigidity and bradykinesia, predominantly in his 